\title{
Neuroactive Steroids: Receptor Interactions and Responses
}

\author{
Kald Beshir Tuem ${ }^{1}$ and Tesfay Mehari Atey ${ }^{2 *}$ \\ ${ }^{1}$ Department of Pharmacology, School of Pharmacy, College of Health Sciences, Mekelle University, Mekelle, Ethiopia, \\ ${ }^{2}$ Clinical Pharmacy Unit, School of Pharmacy, College of Health Sciences, Mekelle University, Mekelle, Ethiopia
}

Neuroactive steroids (NASs) are naturally occurring steroids, which are synthesized centrally as de novo from cholesterol and are classified as pregnane, androstane, and sulfated neurosteroids (NSs). NASs modulate many processes via interacting with gamma-aminobutyric acid (GABA), N-methyl-D-aspartate, serotonin, voltage-gated calcium channels, voltage-dependent anion channels, $\alpha$-adrenoreceptors, X-receptors of the liver, transient receptor potential channels, microtubule-associated protein 2, neurotrophin nerve growth factor, and $\sigma 1$ receptors. Among these, NSs (especially allopregnanolone) have high potency and extensive GABA-A receptors and hence demonstrate anticonvulsant, anesthetic, central cytoprotectant, and baroreflex inhibitory effects. NSs are also involved in mood and learning via serotonin and anti-nociceptive activity via T-type voltage-gated $\mathrm{Ca}^{2+}$ channels. Moreover, they are modulators of mitochondrial function, synaptic plasticity, or regulators of apoptosis, which have a role in neuroprotective via voltage-dependent anion channels receptors. For proper functioning, NASs need

OPEN ACCESS

Edited by:

Jacob Raber,

Oregon Health \& Science University, United States

Reviewed by: Kevin Donald Broad, UCL Institute of Ophthalmology, United Kingdom Ioannis N. Charalampopoulos, University of Crete, Greece

${ }^{*}$ Correspondence:

Tesfay Mehari Atey

tesfay.mehari@mu.edu.et

Specialty section: This article was submitted to

Neuropharmacology,

a section of the journal

Frontiers in Neurology

Received: 15 May 2017 Accepted: 11 August 2017 Published: 28 August 2017

Citation: Tuem KB and Atey TM (2017) Neuroactive Steroids: Receptor Interactions and Responses.

Front. Neurol. 8:442. doi: 10.3389/fneur.2017.00442 to be in their normal level, whereas excess and deficiency may lead to abnormalities. When they are below the normal, NSs could have a part in development of depression, neuro-inflammation, multiple sclerosis, experimental autoimmune encephalitis, epilepsy, and schizophrenia. On the other hand, stress and attention deficit disorder could occur during excessive level. Overall, NASs are very important molecules with major neuropsychiatric activity.

Keywords: neuroactive, steroids, receptors, interactions, responses

\section{OVERVIEW OF NEUROACTIVE STEROIDS (NASs)}

Neuroactive steroids are types of steroids-which are occurring naturally-in which they have an impact on behavioral actions, change excitability of neurons, and results in non-genomic effects and through the interaction with specific neurotransmitter receptors $(1,2)$. Adrenal glands, ovary, and brain are their sites of production either from cholesterol or via metabolism of deoxycorticosterone,

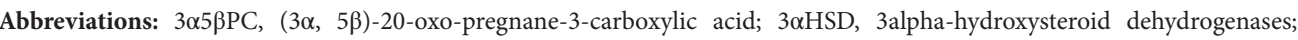
$3 \alpha$-HSOR, 3alpha-hydroxysteroid oxidoreductase; $5 \alpha \mathrm{R}$, 5alpha-reductase; $5 \alpha \mathrm{RI}$, 5alpha-reductase type I; ALLO/AP, allopregnanolone; CA1, Cornu Ammo; CNS, central nervous system; Cyps, cytochrome P450; DHEA, dehydroepiandrosterone; DHEAS, dehydroepiandrosterone sulfate; DHP, dihydroprogesterone; EAE, experimental autoimmune encephalitis; GABA, gamma-aminobutyric acid; GABA-A, gamma-aminobutyric acid type A; GABA-AR, gamma-aminobutyric acid type A receptor; GABA-C, gamma-aminobutyric acid type C; HSD, hydroxysteroid dehydrogenases; LTP, long-term potentiation; MAP2, microtubule-associated protein 2; mIPSCs, miniature inhibitory postsynaptic currents; NASs, neuroactive steroids; NMDA, $N$-methyl-D-aspartate; NPCs, neural progenitor cells; NSs, neurosteroids; NSCs, neural stem cells; PHS, pregnenolone hydro-sulfate; PKC, protein kinase C; PMS, premenstrual syndrome; PR, progestrone receptor; PREG, pregnenolone; PREGS/ PregS/PS, pregnenolone sulfate; PROG, progesterone; StAR, steroidogenic acute regulatory protein; TBPS, t-butylbicyclophosphorothionate; THDOC, tetrahydrodeoxycorticosterone; THP, tetrahydroprogesterone; TRPM, mammalian transient receptor potential melastatin; VD, vitamin D; VDAC, voltage-dependent anion channels; VDR, vitamin D receptor; VGLCCs, L-type voltage-gated $\mathrm{Ca}^{2+}$ channels; VGTCCs, T-type voltage-gated $\mathrm{Ca}^{2+}$ channels.
} 
testosterone, and progesterone-which are their blood-borne precursors (3). Moreover, they are also produced in fetoplacental unit (4). The term "neurosteroids" (NSs) are coined since cholesterol is the precursor for de novo synthesis of NSs centrally (5).

Grossly, NASs can be categorized into three classifications, namely, pregnane NSs, androstane NSs, and sulfated NSs. The pregnane NSs consisted of progesterone derivatives such as allopregnanolone (ALLO) ( $3 \alpha, 5 \alpha$-tetrahydroprogesterone), epiallopregnanolone ( $3 \beta, 5 \alpha$-tetrahydroprogesterone), pregnanolone ( $3 \alpha, 5 \beta$-tetrahydroprogesterone), pregnenolone (PREG), dehydroepiandrosterone (DHEA), and allotetrahydrodeoxycorticosterone (THDOC). The second classification consisted of androstane NSs including both androstanediol and etiocholanone and last sulfated NSs comprised dehydroepiandrosterone sulfate (DHEAS) and pregnenolone sulfate (PREGS) $(6,7)$. Furthermore, vitamin D is categorized as NSs as it affects the brain of younger children and adult population (8).

Dehydroepiandrosterone acts as an antagonist of cortisol and is the most plentiful circulating steroid among the NASs in human being (9). The sulfated form of this NASs-DHEA-S-has a relatively long half-life and in animal models, DHEA-S enhances cognitive and behavioral performance (10). Androstenol is a special type of NSs, acts as a pheromone, and has a higher structural resemblance to gamma-aminobutyric acid-A (GABA-A) receptor modulating NSs and as a result of this, act as a signaling molecule between entities of the alike species through interaction with GABA-A receptors (11).

Neurosteroids have revealed contribution in numerous nueropathophysiological processes, including aggression, mood, energy, general activity, learning, and memory processes (12), excitatory or inhibitory effects of different neurotransmitters, upsurge serotonin levels, and the inhibitory action against certain cortisol effects in the brain $(12,13)$. To realize their role, NSs involve allosteric modulation on GABA (14), N-methyl-Daspartate (NMDA) glutamate (15), serotonin (5-HT3) (16), and alpha-1 receptors (17).

\section{BIOSYNTHESIS OF NASS}

Reduction of the A-ring from testosterone, deoxycorticosterone, and progesterone-which are steroid hormones-results in the formation of NSs (4). These chemicals can be released into the blood and act systemically or synthesized de novo locally, from cholesterol $(5,18)$, in certain brain parts such as in the pineal gland (the major site for neurosteroidogenic organ), cortex, glutamatergic neurons, hippocampus, and cortex (19).

Allopregnanolone and $7 \alpha-\mathrm{OH}$ PREG were exceedingly produced and show vital roles in the Purkinje cell facilitation of survival in the juvenile quail (20) by suggested action via GABA-A receptor (21). Moreover, $3 \alpha$-hydroxysteroid oxidoreductase ( $3 \alpha$-HSOR) and $5 \alpha$-reductase enzymes reduce the precursor steroid-found peripherally in skin and liver-to produce androstanediol, ALLO, and THDOC (22). Other substances are also involved in the induction of the biosynthesis of NASs: retinoic acids and vitamin D3 (VD3) induce neurosteroid production in human glial cells in culture (23), VD3 via induction of
CYP11A1 and HSD3B1 (steroidogenic genes), which is mediated by vitamin $\mathrm{D}$ receptor (24).

Some factors affect the biosynthesis of NASs. The mRNA expression of $5 \alpha$-reductase type I $(5 \alpha-\mathrm{RI})$ is markedly downregulated $(\sim 50 \%)$ by social isolation in neurons of the cortex, hippocampus, and basolateral nucleus of the amygdala. For instance, $65-75 \%$ and smaller $(\sim 35 \%)$ decrease of $5 \alpha$-RI mRNA levels were observed in dentate gyrus granule cells and CA3 glutamatergic pyramidal neurons, and frontal cortex pyramidal neurons (layer V/VI glutamatergic), respectively. Therefore, the anxiety and aggressive behavior seen in mice, which is socially isolated, is due to decreased ALLO biosynthesis in glutamatergic neurons of basolateral nucleus of the amygdala and frontal cortex (25) (Figure 1).

\section{MECHANISMS OF ACTION OF NASs}

The mechanism of action of NASs can be classified as either (a) classical intracellular binding-in which this effect is described as a relatively slow genomic effects of NASs, (b) effect on membrane receptors and ion channels-in which this effect is also described as a rapid non-genomic effects of NASs, or (c) due to their metabolic interconversion to traditional steroids in the brain whereas some steroids led to rapid membrane effects through interaction with certain neurotransmitter receptors $(6,26)$. In summary, NSs predominantly interact with ion channels and neuronal membrane receptors-but not primarily through interaction with intracellular receptors-and thereby modulate brain excitability (27), preferably through direct modulation of ion channels that are ligand-gated, remarkably GABA-A receptors (28).

\section{REGULATION OF NASs}

In the supraoptic nucleus, oxytocin regulates neurosteroid modulation of GABA-A receptors after parturition, since the activity of protein kinase $\mathrm{C}$ (PKC) and sensitivity of GABA-A receptor to ALLO in the supraoptic nucleus are mainly determined by the magnitude of activation of oxytocin receptor. Besides this, the GABA-A receptors are ALLO-resistant in breastfeeding mothers due to the presence of high level of oxytocin (29). The presence of relatively high concentrations of endogenous phosphatase during late pregnancy enhances the sensitivity of ALLO to GABA-A receptors. On the other hand, sensitivity of ALLO is restored by these phosphatases stimulation - which are endogenous - or PKC inhibition when NSs are becoming insensitive to GABA-A receptors (29). Instead, effect of the endogenous phosphatases and PKC on dissimilar phosphorylation sites or varying proteins of GABA, which are found on postsynaptic sites, may be prominent (30).

\section{METABOLISM OF NASs}

Neuroactive steroids undergo multiple stages for their metabolism. The brain microsomes process the two main NSs-PREG and DHEA - and convert them into their corresponding $7 \alpha$-hydroxylated derivatives. Consequently, the concentration of active metabolites may be regulated by the production of these $7 \alpha$-hydroxylated derivatives of PREG (progesterone) 


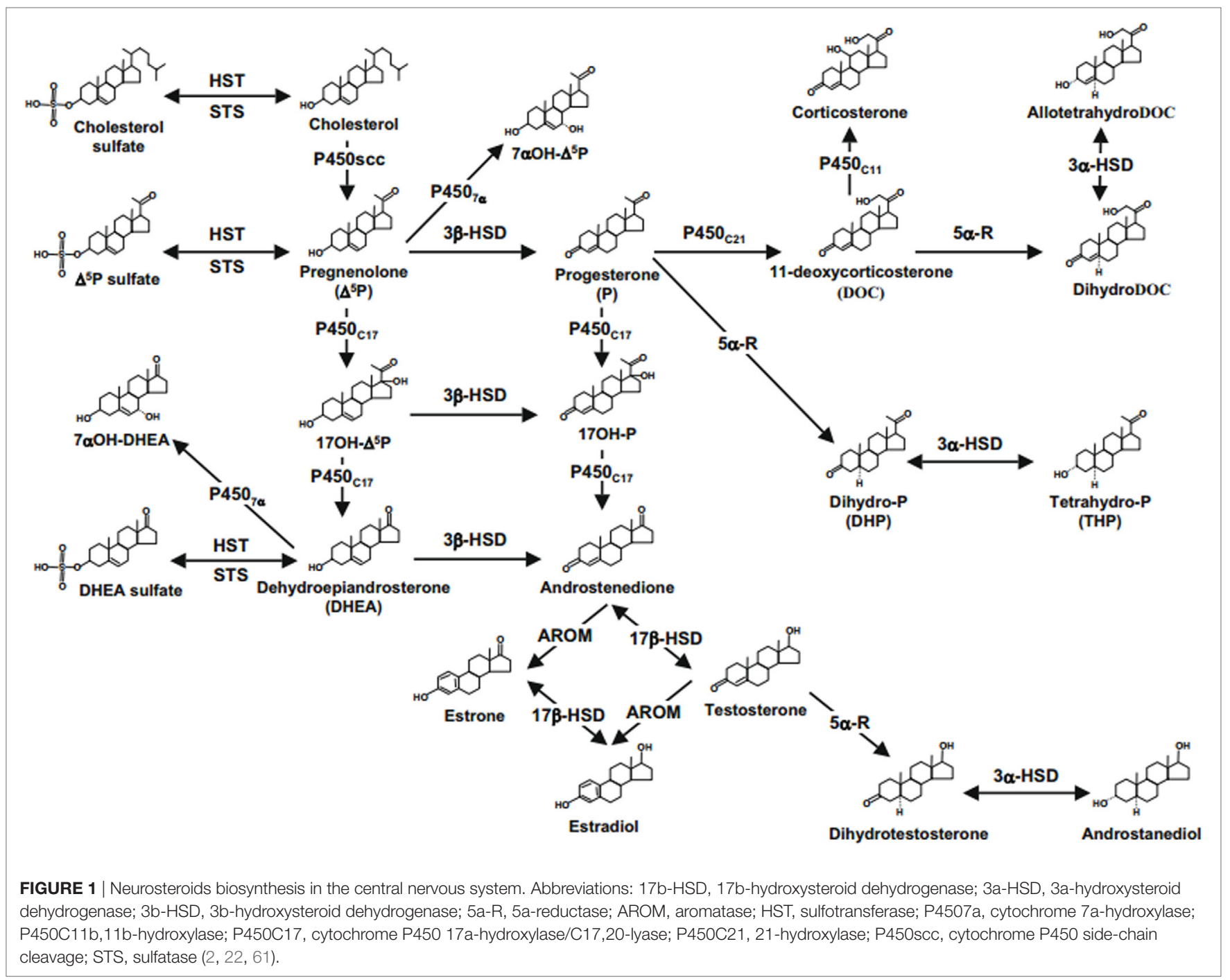

(31) and DHEA (androstenedione, a precursor of testosterone) (32). Furthermore, detection of a little amount of 7 beta-OH metabolites of DHEA and PREG has been possible, but their characterization was not definite (33).

\section{EFFECT OF NASs}

\section{Effect of NSs on Receptors of Gamma- Aminobutyric Acid \\ Effect on Gamma-Aminobutyric Acid-A Receptors}

Gamma-aminobutyric acid-A receptors (GABA-A receptors) are major targets for central nervous system (CNS) actions of NSs (34). The GABA-A receptor function can be regulated by the NSs negatively or positively, based on the chemical structure of the steroid molecule $(27,35)$. Secondary to the activation of the inotropic GABA-A receptors by NASs, chloride ion influx and causes neuronal membrane hyperpolarization (36).

The GABA-A receptors have novel subunit dependence of NSs action (34). The neurosteroid THDOC favorably augment the receptor with $\sigma$ subunit among the seven different classes of subunits ( $\alpha 1-6, \beta 1-3, \gamma 1-3, \sigma 1-3, \delta, \varepsilon, \theta)$. High (micromolar) and low (nanomolar) levels of NSs cause direct activation of GABA-A receptors and allosteric augmentation of GABA-regulated currents, respectively (37). However, changing in the modulation of NSs and inhibition of intact GABA are observed in neurons found in thalamic relay of mice without delta subunit (34). Inhibition of PKC activity abolishes the effect of THDOC on GABA-A receptors through increased $\alpha-4$ subunit phosphorylation and its accumulation on cell surface by accelerating the $\alpha-4$ subunit insertion into cell membrane without altering their endocytosis (38). The increased effect of THDOC on the phosphorylation of $\alpha-4$ subunit and its expression on the cell surface is counteracted by S443 mutation, which is the major site of phosphorylation of PKC in the $\alpha-4$ subunit (39).

Neurosteroids increased expression of $\alpha_{4} \beta \gamma_{2}$ GAB-A receptors at Cornu Ammo (CA1) pyramidal cell synapses. The diminution in decay time for GABAergic miniature inhibitory postsynaptic currents following short-term NSs exposure is mediated by this increased expression - containing $\alpha 4-\mathrm{GAB}-\mathrm{A}$ receptors localized to synaptic sites (40). 
During stress, the balance between inhibition and excitation may be maintained by NSs, in which GABA-A receptor regulation is influenced by the levels of and duration of exposure to NSs (41). The plasma level of THDOC is elevated by about three times in the presence of stress (42). From the NASs, ALLO, THDOC, and androstanediol are powerful modulators of the GABA-A receptor (through positive allosteric modulation) and bring behavioral effects at low concentrations $(1,43,44)$. Allopregnanolone was fully effective in suppressing GnRH release, mediated by interaction with the GABA-A receptor. Moreover, ALLO suppressive action on $\mathrm{GnRH}$ release in vitro is completely offset by GABA-A antagonistic NASs, PREG-S (31).

Enhancement of NSs due to reduced sensitivity of GABAergic synaptic transmission in dentate granule cells lead to the blockage of seizure propagation into the hippocampus (45). In women, seizure exacerbation during the perimenstrual period is contributed by the loss of NSs sensitivity of synaptic inhibition. In addition, withdrawal and elevated concentrations of NSs-observed in the mid-cycle-leads to exacerbation of seizure and anticonvulsant action, respectively (46). In the spinal cord, obliteration of induction of activity-dependent reflex plasticity is mediated by modulation of GABA-A receptors dependent inhibition as a result of the activity of the progesterone and its metabolites (ALLO and THDOC) (47).

Neurosteroids are potent cytoprotectants when they interact with neuronal GABA-A receptor. The potency and efficacy of NSs is affected by their structure. Sulfated NSs (PREGS and DHEAS) fully efficacious (about 70\%) than the non-sulfated (AP and $17 \alpha-\mathrm{OH}-\mathrm{AP}$ ). This is further substantiated by the structural activity analysis that indicated the association of an increase in potency but decrease in efficacy of the cytoprotectants with the lack of the double bond between C-5 and C- 6 in AP and $17 \alpha-\mathrm{OH}-\mathrm{AP}$ and/or the hydroxyl group in the $\alpha$-position (48).

Dehydroepiandrosterone and its sulfated metabolite, DHEA-S (more potent and more efficacious than the parent compound), which interacted with the picrotoxin/TBPS (t-butylbicyclophosphorothionate) binding site in a competitive manner (49), decreased GABA-A receptor-mediated responses on serotonin (5-HT) neuronal firing regulation, and vice versa. Androsterone and its parent compound (DHEA) can affect anxiety, cognition, and mood through enhancement of the GABA-A mediated response (50). Inhibition of NMDA receptor and potentiation of GABA-A receptor function, which will add on the clinical profile of anesthetic NASs - is mediated by another neurosteroid compound: $(3 \alpha, 5 \beta)$-20-oxo-pregnane3 -carboxylic acid $(3 \alpha 5 \beta \mathrm{PC})$. Notwithstanding, a NAS with a better clinical activity can be produced by augmenting blockage of NMDA receptor and reducing GABA-A receptor blockage since a direct correlation of the optimal property of anesthetic, anticonvulsant, and neuroprotective with high micromolar concentrations of $3 \alpha 5 \beta \mathrm{PC}$-needed for blocking effect on GABA-A receptors-might not be observed (51).

Stereospecific non-genomic activity on GABA-A receptor results in sharp increases in blood concentrations of $3 \alpha-\mathrm{OH}$ DHP - the neuroactive metabolite of progesterone-and ultimately leads to enhancing the baroreflex inhibition of brainstem rostral ventrolateral medulla neurons (52).

\section{Effect on Gamma-Aminobutyric Acid-C Receptors}

The interaction of NASs with the $\rho 1-\mathrm{GABA}-\mathrm{C}$ receptor-which is very specific chiral sites-and $3 \alpha$ configuration of GABA-C receptor is required for all steroid actions. NSs have multiple sites for interaction with the $\rho 1$ receptor of GABA-C than GABA-A. However, a similarity in qualitative measurements and GABA-A receptor potentiation was observed in sites mediating $5 \beta$-reduced steroids inhibition and potentiation of the $\rho 1$ receptor by $5 \alpha$ receptors (53).

Allopregnanolone, alphaxalone, and 5 $\alpha$-THDOC prolong the decay time and potentiate the GABA-induced currents. On the contrary, the $\rho 1-G A B A-e v o k e d$ current is inhibited by the co-administration of GABA with $5 \beta$-THDOC, pregnenolone, or $5 \beta$-DHP. The degree of inhibition and potentiation of $\rho 1-\mathrm{GABA}$ provoked currents by NASs is reliant on the concentration of GABA. Since the application of GABA alone, following treatment with NAS, did not revert back to the control level for an extended period of time, a prolonged and persistent effect was observed on the effects of the NASs on $\rho 1$ receptor channels. The $5 \alpha$ derivatives were potentiators (only at exceedingly low concentrations of GABA), whereas the $5 \beta$ compounds were inhibitors of the GABA-evoked currents (54).

\section{Effect of NSs on $\mathbf{N}$-Methyl-D-Aspartate Receptors}

Neurosteroids (PS and PHS) control the NMDA receptors dependent (4) and independent (L-type calcium channeldependent) long-term potentiation (LTP) positively at a lower dose (1-5 mM) and negatively at a higher concentration (15 mM) (sigma-receptor function blockade) (55). Positive modulation is through increased $\mathrm{Ca}^{2+}$ influx into presynaptic NMDA receptors (containing NR2D subunits) that raise the probability of glutamate discharge in hippocampal slices as studied in rats less than 6 days age $(56,57)$. The positive regulation was observed to be negatively affected by antepartum ethyl alcohol exposure due to a change in NMDA receptor phosphorylation (58).

Pregnenolone sulfate stimulates a continued increase in the NMDA effect from 200 to $400 \%$, by integration of extra subunit specific $(\sigma 1)$ receptors into the surface membrane $(57,59)$. This integration requires G-protein-coupled activation of PKC and PLC and increased $\mathrm{Ca}^{2+}$ ion (Figure 2) (59). The movement of NMDA receptors between the membrane and intracellular pools is required for maintenance and plasticity of synaptic connections; however, deregulation of the receptor movement has been associated with neuropsychiatric disorders (60). Hence, NMDA receptor surface expression plays a great role in disorders of NMDA receptor trafficking or provides a basis for the development of therapeutic interventions (59).

\section{Effect of NSs on Voltage-Gated Calcium Channel Receptors \\ Effect on L-Type Voltage-Gated Calcium Channels}

Allopregnanolone $(\mathrm{AP} \alpha) \quad(3 \alpha$-hydroxy-5 $\alpha$-pregnan-20-one) promotes proliferation of hippocampal neural progenitor cells in rat and cerebral cortical neural stem cells (NSCs) in human at a nanomolar levels, and inhibits the proliferation of polysialylated 


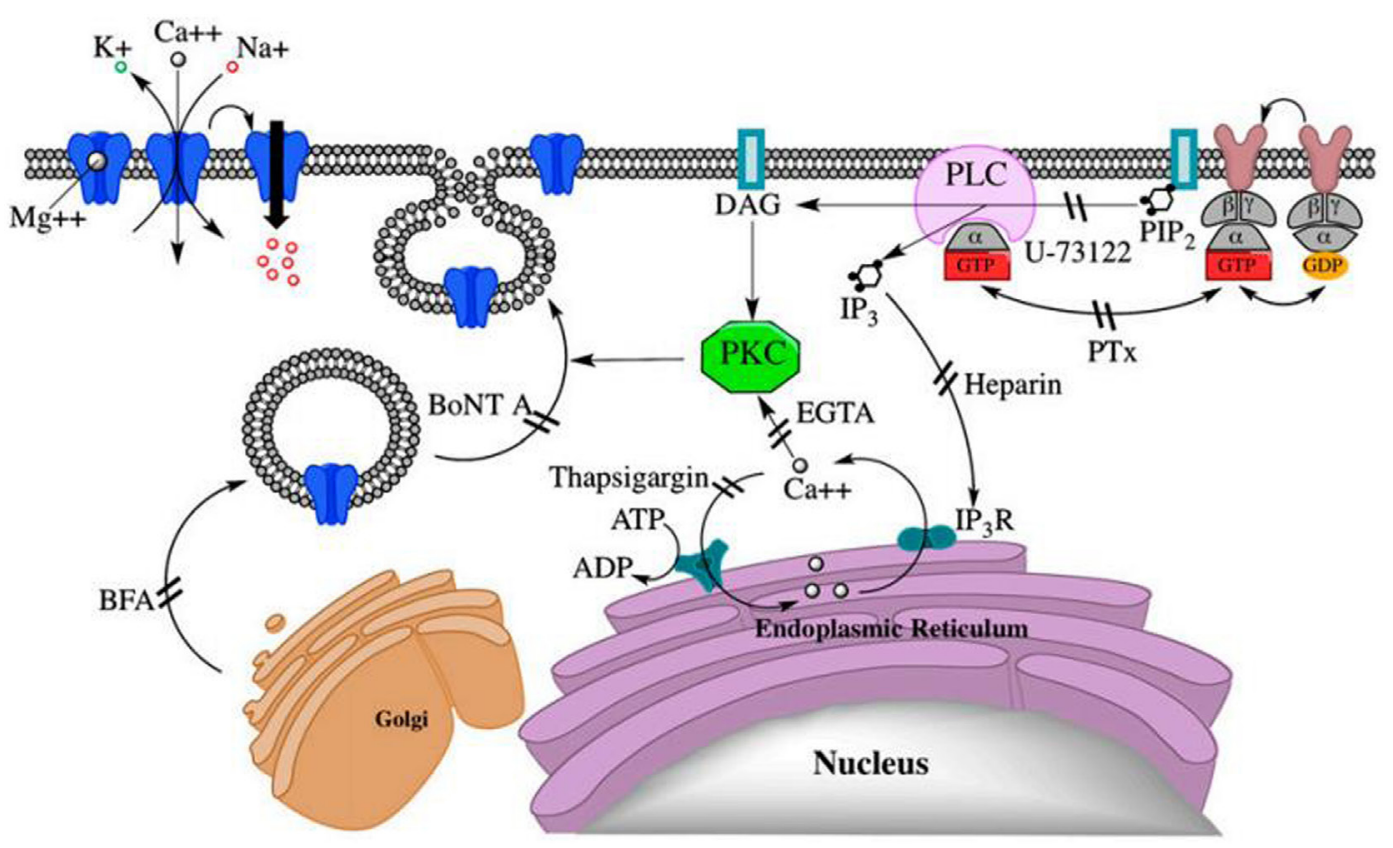

FIGURE 2 | PregS-stimulated trafficking of functional N-methyl-D-aspartate (NMDA) receptors to the cell surface via a non-canonical G protein-, PLC-, Ca2+-, and protein kinase C (PKC)-dependent mechanism. DAG, diacylglycerol; IP3R, IP3 receptor; NMDA, (N)methyl-D-aspartate; PIP2, phosphatidylinositol 4,5-bisphosphate (59).

form of the neural cell adhesion molecule (PSA-NCAM) at micromolar levels (62). This mechanism requires activation of L-type voltage-gated $\mathrm{Ca}^{2+}$ channels (VGLCCs) (63). In mature neurons, $\mathrm{AP} \alpha$ increases chloride influx via allosteric modulation of the GABA-A receptor, thereby hyperpolarizing the neuronal membrane potential and decreasing neuron excitability (36). In marked contrast, it leads to an efflux of chloride in immature neurons, which causes depolarization of the membrane and opening of VGLCCs, then rises in intracellular $\mathrm{Ca}^{2+}(63,64)$. Finally, this can trigger calcium-dependent mechanisms of mitosis in early precursor cells and human NSCs to promote neurogenesis (65).

\section{Effect on T-Type Voltage-Gated Calcium Channels}

The $5 \beta$-reduced NASs are powerful inhibitors of the T-type $\mathrm{Ca}^{2+}$ channels in rat peripheral sensory neurons in vitro and very effective peripheral anti-pain agents in vivo, strongly proposing that T-type $\mathrm{Ca}^{2+}$ channels are involved in peripheral somatic nociception (66). Thus, the $5 \beta$-reduced steroids are hopeful new agents for studying the role of T-type $\mathrm{Ca}^{2+}$ channels in peripheral nociception and are potentially useful targets for the development of new pain therapies (67).

\section{Effect of NSs on Serotonin Receptor}

Neurosteroids (DHEA) interact with ligand-gated serotonin (5-HT) receptors to enhance their firing action through $\sigma 1$ receptors (68). This stimulates neurogenesis in the hippocampal dentate gyrus and shields it from glucocorticoids' detrimental attack (69).

Since DHEAs interact with $\sigma 1$ receptors to bring their effect, $\sigma 1$ receptor antagonists could eliminate the effect of DHEAs, whereas agonists of the receptor could simulate the blocking effect of DHEAs on 5-HT-evoked glutamate release via activation of $\mathrm{Gi}$ protein pyramidal cells of rat prelimbic cortex. At a lower concentration $(1 \mu \mathrm{M})$, DHEAs could significantly hinder the 5-HT-evoked glutamate release in brain region by preventing its binding with 5-HT3. In reverse, DHEAs effect can be lessened with the rise in concentration due to promoting spontaneous glutamate release (70).

There is a relationship between central serotonergic activity and circulating ALLO concentrations. This is evidenced by an increase in ALLO concentrations in luteal phase after the administration of L-tryptophan in both controls and women with premenstrual syndrome (PMS) (greater increase in ALLO concentrations with PMS) (71).

\section{Effect of NSs on $\alpha_{2}$-Adrenergic Receptors}

Neurosteroids (PREGS) blocks LTP of excitatory synapses in rat medial prefrontal cortex (mPFC) via interaction with $\alpha_{2}{ }^{-}$ adrenoreceptors secondary to enhancement of Gi proteins. After treatment of mPFC slices with the $\alpha_{2}$-adrenoreceptor inhibitor "yohimbine," the blocking effect of PREGS on the induction of LTP was completely inhibited (72).

\section{Effect of NSs on Transient Receptor Potential Channels}

Mammalian transient receptor potential melastatin (TRPM) proteins-such as TRPM1 and TRPM3-get together into ion transporting canals and respond to temperature, osmolarity, various chemical signals, change in membrane voltage, oxidative stress, and intracellular calcium (73). PREGS, pregnenolone, 
and epipregnanolone sulfate were found to potentiate TRPM3 activity. As compared to pregnenolone, PREGS shows comparable potency but greater than 10 -fold higher intrinsic activity $(74,75)$, and it stimulates TRPM3 activity via heat-dependent modulation (76).

\section{Effect of NSs on Reward Pathway via the o1 Receptor}

The $\sigma 1$ receptor is an intracellular neuronal protein found in endoplasmic reticular, plasma, nuclear, and mitochondrial membranes. The ligands of $\sigma 1$ receptor potently modulate intracellular $\mathrm{Ca}^{2+}$ mobilizations and extracellular $\mathrm{Ca}^{2+}$ influx $(77,78)$. Pregnenolone, DHEA, and progesterone interfere with cocaineinduced reward path way in mice. DHEA and its precursor PREG facilitate cocaine-induced conditional place preference acting as $\sigma 1$ receptor agonists (79).

\section{Effect of NSs on Liver X Receptors (LXRs)}

Liver X receptors have two isoforms, $\mathrm{LXR} \alpha(\mathrm{NR} 1 \mathrm{H} 3)$ and $\mathrm{LXR} \beta$ $(\mathrm{NR} 1 \mathrm{H} 2)$, classified under nuclear receptor superfamily. $\mathrm{LXR} \alpha$ is highly found in liver and minimally in the intestine, macrophages, adipose tissue, lung, kidney, and adrenal gland; whereas LXR $\beta$ is broadly expressed (80). Oxysterols (oxidized cholesterol) bind with LXRs and induce expression of genes which eradicate harmful cholesterol level by efflux through ATP-binding cassette family of transporters (81). Activation of LXRs promote cholesterol disposal, steroidogenesis in the adrenal gland, regulation of StAR expression, restores normal StAR mRNA levels and completely restores the mRNA levels of P450scc to non-diabetic levels, and raises the local levels of NASs like PROG and DHP. These functions play a role in protecting diabetes patients from peripheral neuropathy (82).

\section{Effect of NSs on Voltage-Dependent Anion Channels (VDAC)}

Interactions of NASs with VDAC isoforms (prominent brain protein) are important to regulate mitochondrial function, synaptic plasticity, or apoptosis. A role in avoiding apoptosis explains the neuroprotective actions of the NASs (83).

\section{Effect of NSs on Microtubule-Associated Protein 2 (MAP2)}

Pregnenolone and its synthetic analog-MePREG interacts with MAP2 at an unknown binding site. Then, it stimulates microtubule polymerization (rat brain and from PC12 cells) and the extension of neuritis in pheochromocytoma cells that are exposed to nerve growth factor (NGF) (84).

\section{Effect of NSs on Neurotrophin NGF Receptors}

Acting as a neurotrophic factor, DHEA affects neuronal survival and neurogenesis during development and in aging in the brain via interacting with pro-survival TrkA and pro-death p75 (NTR) membrane receptors of neurotrophin NGF. This stimulation inhibits the apoptotic loss of NGF receptor positive sensory and sympathetic neurons. Furthermore, it provides a mechanistic

TABLE 1 | Effect of neurosteroids on various receptors.

\begin{tabular}{|c|c|c|c|}
\hline Receptor & Neurosteroid & Effects & Reference \\
\hline GABA-A & $\begin{array}{l}\text { THDOC, } \\
\text { androstanediol, AP, } \\
\text { PREGS, } 3 \alpha 5 \beta \text { PC }\end{array}$ & $\begin{array}{l}\text { Neuronal membrane hyperpolarization, cytoprotectants, anesthetic, anticonvulsant, neuroprotective (+), suppressing } \\
\mathrm{GnRH} \text { release, blockage of seizure propagation into the hippocampus }(-)\end{array}$ & $(27,34-36$ \\
\hline GABA-C & $\begin{array}{l}\text { AP, } 5 \alpha-\text { THDOC, } \\
5 \beta \text {-DHP }\end{array}$ & Potentiation of GABA-induced currents $(+)$ at high concentration by $5 \alpha$ and $(-)$ by $5 \beta$ & $(53,54)$ \\
\hline NMDA & PS, PHS & Raise glutamate discharge in hippocampal slices $(+)$ at lower dose and $(-)$ at higher dose & $(55-57)$ \\
\hline $\begin{array}{l}\text { L-type } \\
\text { VGLCCs }\end{array}$ & $\mathrm{AP} \alpha$ & Promotes proliferation of hippocampal neural progenitor cells at nanomolar level, promote neurogenesis $(+)$ & $(62,65)$ \\
\hline $\begin{array}{l}\text { T-type } \\
\text { VGLCCs }\end{array}$ & $5 \beta$-reduced NASs & Anti-pain agents in vivo (-) & $(66)$ \\
\hline Serotonin & AP, DHEA & Neurogenesis in hippocampal dentate gyrus $(+)$ & (69) \\
\hline$\alpha 2$-adrenergic & PS & Blocks long-term potentiation (-) & $(72)$ \\
\hline TRPM & $\begin{array}{l}\text { PREGS, PS, } \\
\text { epipregnanolone } \\
\text { sulfate }\end{array}$ & $\begin{array}{l}\text { Respond to temperature, osmolarity, various chemical signals, change in membrane voltage, oxidative stress, and } \\
\text { intracellular calcium (+) }\end{array}$ & $(73-76)$ \\
\hline$\sigma 1$ (Reward) & PEG, DHEA, PR & facilitated an acquisition of cocaine-induced conditioned place preference $(+)$ & (79) \\
\hline Liver $\mathrm{X}$ & $\begin{array}{l}\text { DHP } \\
\text { PROG }\end{array}$ & Protecting diabetes patients from peripheral neuropathy $(+)$ & (82) \\
\hline VDAC & NAS & Regulate mitochondrial function, synaptic plasticity, regulators of apoptosis (+) & (83) \\
\hline MAP2 & PREG, MePREG & stimulate microtubule polymerization (+) & (84) \\
\hline NGF & DHEA & neuronal survival and neurogenesis, immune, reproductive, cardiovascular systems (+) & (85) \\
\hline
\end{tabular}

$(+)=$ potentiation of the receptor, $(-)=$ inhibition of the receptor.

3 $\alpha 5 \beta P C,(3 \alpha, 5 \beta)-20$-oxo-pregnane-3-carboxylic acid; ALLO/AP, allopregnanolone; DHEA, dehydroepiandrosterone; DHEAS, dehydroepiandrosterone sulfate; DHP,

dihydroprogesterone; GABA-A, GABA-C, gamma-aminobutyric acid type C; MAP2, microtubule-associated protein 2; NASs, neuroactive steroids; NMDA, N-methyl-D-

aspartate; PHS, pregnenolone hydro-sulfate; PR, progesterone receptor; PREG, pregnenolone; PREGS/PregS/PS, pregnenolone sulfate; PROG, progesterone; THDOC,

tetrahydrodeoxycorticosterone; TRPM, mammalian transient receptor potential melastatin; VDAC, voltage-dependent anion channels; VGLCCs, L-type Voltage-gated Ca ${ }^{2+}$ channels;

VGTCCs, T-type voltage-gated $\mathrm{Ca}^{+2}$ channels. 
explanation for the multiple actions of DHEA in other peripheral biological systems expressing NGF receptors, such as the immune, reproductive, and cardiovascular systems (85) (Table 1).

\section{INVOLVEMENT OF NASS IN NEUROLOGICAL DISEASES}

Epilepsy-related with menstruation (catamenial epilepsy) currently has no specific approved treatments. This kind of epilepsy is as a result of enhanced excitability due to withdrawal of NSs, which in turn leads to upregulation of $\alpha 4$ subunit and linked with upregulation of Egr3 and reduced synaptic inhibition. In addition, neurosteroid withdrawn mice were amazingly less sensitive to the antiseizure effects of diazepam, and progesterone receptor (PR) knockout animals were also less sensitive to the protective actions of diazepam during neurosteroid withdrawal (86). Neurosteroid (ALLO) has broad-spectrum anticonvulsant activity and recently it is approved for investigational use to treat an individual with prolonged super refractory status epilepticus (87). Other NS like AP $\alpha$ also has anxiolytic and sedative-hypnotic properties with no indicated toxicological adverse events in healthy human volunteers and in children with refractory infantile spasms (88-90). Further investigations are presently ongoing to identify the neurogenic potential of $\mathrm{AP} \alpha$ in rodent models of aging and Alzheimer's disease (AD) (63).

The concentrations of testosterone, cortisol, PROG, DHEA, DHEAS, and estrogen levels have been found to be changed in some patients with schizophrenia. The level of DHEA contrariwise associated with negative symptom severity in drug-free men with first-episode psychosis (91). In major depressive episodes, NS, mainly ALLO and pregnenolone, are found to be diminished in both the cerebrospinal fluid (CSF) and the plasma of untreated patients (25). However, following effective psychopharmacological treatment concentrations of ALLO in depressed patients increase to normal levels. Several findings support the hypothesis of an antidepressant effect of ALLO (92).

Stress-induced groups of rats showed declined amount of DHEA-S, which indicates that DHEA may play an important

\section{REFERENCES}

1. Paul SM, Purdy RH. Neuroactive steroids. FASEB J (1992) 6:2311-22.

2. Kena R, Genevieve S, Karin D, Marie P, Ruth B, Margrit S, et al. Cyp7b, a novel brain cytochrome P450, catalyzes the synthesis of neurosteroids 7a-hydroxy dehydroepiandrosterone and 7a-hydroxy pregnenolone. Proc Natl Acad Sci U S A (1997) 94:4925-30. doi:10.1073/pnas.94.10. 4925

3. Purdy RH, Morrow AL, Blinn JR, Paul SM. Synthesis, metabolism, and pharmacological activity of 3-alpha-hydroxysteroids which potentiate GABA receptor mediated chloride ion uptake in rat cerebral cortical synaptosomes. J Med Chem (1990) 33:1572-81. doi:10.1021/jm00168a008

4. Reddy DS. Neurosteroids: endogenous role in the human brain and therapeutic potentials. Prog Brain Res (2010) 186(113-137):2010. doi:10.1016/ B978-0-444-53630-3.00008-7

5. David H, Staffan J. Neurosteroid modulation of synaptic and GABA-evoked currents in neurons from the rat medial preoptic nucleus. JNeurophysiol (1999) 82:143-51.

6. Mellédo J-ML, Baker GB. Neuroactive steroids and anxiety disorders. J Psychiatry Neurosci (2002) 27:161-5. role in the development of adaptive responses to a stressful event (93). Higher blood level of DHEA and DHEAS were related with less experience of symptoms in attention deficit hyperactivity disorder (ADHD), in particular, hyperactivity symptomatology. However, the effect in ADHD patients remains elusive (94). Alterations in gene expression of the enzymes which synthesize NSs may be involved in the pathology of AD. In early AD, there is an attempt to increase the biosynthesis of NSs and NASs through increased mitochondrial import of cholesterol (95).

The amount of AP and DHEA showed significant reduction in specimens of multiple sclerosis white matter compared to controls. Allopregnanolone has a role in controlling neuroinflammation and protection of demyelination and axonal loss in models of multiple sclerosis by interacting with GABA-A receptor. Experimental autoimmune encephalitis (EAE) is characterized by disordered neurosteroidogenic machinery, which causes reduced expression of the enzymes (3-alpha-hydroxysteroid dehydrogenase) involved in AP biosynthesis, related with reduced AP levels in the CNS. Since AP has a role in controlling neuroinflammation and protection of demyelination and axonal loss, it also used for the treatment of EAE associated myelin and axonal injury (96).

Levels of allopregnanolone and 5-DHP were found reduced in the CSF of Parkinson's disease (PD) patients signifying a part for these progesterone metabolites in the disease. Moreover, the enzymes which synthesize allopregnanolone, mRNA expression of 5-reductase type 1 (SRD5A1) was significantly reduced in peripheral blood mononuclear cells of $\mathrm{PD}$ patients, proposing a generalized defect in the enzymatic machinery that regulates the metabolism of progesterone (97).

\section{AUTHOR CONTRIBUTIONS}

$\mathrm{KT}$ and TA conducted the review and edited the manuscript.

\section{FUNDING}

The study was not supported by any funding agent.

7. Carta MG, Bhat KM, Preti A. GABAergic neuroactive steroids: a new frontier in bipolar disorders. Behav Brain Func (2012) 8:61. doi:10.1186/17449081-8-61

8. Groves NJ, McGrath JJ, Burne THJ. Vitamin D as a neurosteroid affecting the developing and adult brain. Ann Rev Nutr (2014) 34:117-41. doi:10.1146/ annurev-nutr-071813-105557

9. Kalimi M, Shafagoj Y, Loria R, Padgett D, Regelson W. Anti-glucocorticoid effects of dehydroepiandrosterone (DHEA). Mol Cell Biochem (1994) 131:99-104. doi:10.1007/BF00925945

10. Maingat FG, Maria JP, Amber MP, Pornpun V, Farshid N, Samir A, et al. Neurosteroid-mediated regulation of brain innate immunity in HIV/AIDS: DHEA-S suppresses neurovirulence. FASEB J (2013) 27:725-37. doi:10.1096/ fj.12-215079

11. Kaminski RM, Marini H, Ortinski PI, Vicini S, Rogawski MA. The pheromone androstenol ( $5 \alpha$-androst-16-en-3 $\alpha$-ol): is a neurosteroid positive modulator of GABA-A receptors. J Pharmacol Exp Ther (2006) 317:694-703. doi:10.1124/ jpet.105.098319

12. Wolkowitz OM, Reus VI, Keebler A, Nelson N, Friedland M, Brizendine L, et al. Double-blind treatment of major depression with dehydroepiandrosterone. Am J Psychiatry (1999) 156:646-9. 
13. Rupprecht R, Holsboer F. Neuroactive steroids: mechanism of action and neuropsychopharmacological perspectives. Trend Neurosci (1999) 22:410-6. doi:10.1016/S0166-2236(99)01399-5

14. Lambert JJ, Belelli D, Hill-Venning C, Peters JA. Neurosteroids and GABAA receptor function. Trend Pharmacol Sci (1995) 16:295-303. doi:10.1016/ S0165-6147(00)89058-6

15. Park-Chung M, Wu FS, Farb DH. 3 alphahydroxy-5 beta-pregnan-20-one sulfate: a negative modulator of the NMDA-induced current in cultured neurons. Mol Pharmacol (1994) 46:146-50.

16. Wetzel CH, Hermann B, Behl C, Pestel E, Rammes G, Zieglgansberger W, et al. Functional antagonism of gonadal steroids at the 5-hydroxytryptamine type 3 receptor. Mol Endocrinol (1998) 12:1441-51. doi:10.1210/mend.12.9.0163

17. Maurice T, Urani A, Phan VL, Romieu P. The interaction between neuroactive steroids and the sigma-1 receptor function: behavioral consequences and therapeutic opportunities. Brain (2001) 37:116-32. doi:10.1016/ S0165-0173(01)00112-6

18. Baulieu EE, Robel P, Schumacher M. Neurosteroids: beginning of the story. Int Rev Neurobiol (2001) 46:1-32. doi:10.1016/S0074-7742(01)46057-0

19. Appelgren LE. Sites of steroid hormone formation. Autoradiographic studies using labelled precursors. Brain Res (1967) 764:173-8.

20. Haraguchi S, Hara S, Ubuk T, Mita M, Tsutsuia K. Possible role of pineal allopregnanolone in Purkinje cell survival. Neuroscience (2012) 109:21110-5. doi:10.1073/pnas.1210804109

21. Griffin LD, Gong W, Verot L, Mellon SH. Niemann-pick type C disease involves disrupted neurosteroidogenesis and responds to allopregnanolone. Nat Med (2004) 10:704-11. doi:10.1038/nm1073

22. Do Rego JL, Seong JY, Burel D, Leprince J, Luu-The V, Tsutsui K, et al. Neurosteroid biosynthesis: enzymatic pathways and neuroendocrine regulation by neurotransmitters and neuropeptides. Front Neuroendocrinol (2009) 30:259-301. doi:10.1016/j.yfrne.2009.05.006

23. Kushida A, Tamura H. Retinoic acids induce neurosteroid biosynthesis in human glial GI-1 cells via the induction of steroidogenic genes. J Biochem (2009) 146:917-23. doi:10.1093/jb/mvp142

24. Yagishita T, Kushida A, Tamura H. Vitamin D3 enhances ATRA-mediated neurosteroid biosynthesis in human glioma GI-1 cells. JBiochem (2012) 152:285-92. doi:10.1093/jb/mvs074

25. Agís-Balboa R, Pinna G, Pibiri F, Kadriu B, Costa E, Guidotti A. Downregulation of neurosteroid biosynthesis in corticolimbic circuits mediates social isolation-induced behavior in mice. Proc Natl Acad Sci U S A (2007) 104:18736-41. doi:10.1073/pnas.0709419104

26. Rupprecht R, Reul JM, Trapp T, van Steensel B, Wetzel C, Damm K, et al. Progesterone receptor-mediated effects of neuroactive steroids. Neuron (1993) 11:523-30. doi:10.1016/0896-6273(93)90156-L

27. Reddy DS. Pharmacology of endogenous neuroactive steroids. Crit Rev Neurobiol (2003) 15:197-234. doi:10.1615/CritRevNeurobiol.v15.i34.20

28. Lambert JJ, Belelli D, Peden DR, Vardy AW, Peters JA. Neurosteroid modulation of GABA-A receptors. Prog Neurobiol (2003) 71:67-80. doi:10.1016/j. pneurobio.2003.09.001

29. Koksma JJ, van Kesteren RE, Rosahl TW, Zwart R, Smit AB, Lüddens $H$, et al. Oxytocin regulates neurosteroid modulation of GABA-A receptors in supraoptic nucleus around parturition. J Neurosci (2003) 23:788-97.

30. Kneussel M, Betz H. Clustering of inhibitory neurotransmitter receptors at developing postsynaptic sites: the membrane activation model. Trends Neurosci (2000) 23:429-35. doi:10.1016/S0166-2236(00)01627-1

31. Jung-Testas I, Hu ZY, Baulieu EE, Robel P. Neurosteroids: biosynthesis of pregnenolone and progesterone in primary cultures of rat glial cells. Endocrinology (1989) 125:2083-91. doi:10.1210/endo-125-4-2083

32. Robel P, Corpechot C, Clarke C, Groyer A, Synguelakis M, Vourc'h C, et al. Neuroendocrine Molecular Biology. New York: Plenum Press (1986). p. 367-77.

33. Akwa Y, Morfin RF, Robel TP, Baulie EE. Neurosteroid metabolism 7axhydroxylation of dehydroepiandrosterone and pregnenolone by rat brain microsomes. Biochem J (1992) 28:959-64. doi:10.1042/bj2880959

34. Porcello DM, Huntsman MM, Mihalek RM, Homanics GE, Huguenard JR. Intact synaptic GABAergic inhibition and altered neurosteroid modulation of thalamic relay neurons in mice lacking $\delta$ subunit. J Neurophysiol (2003) 89:1378-86. doi:10.1152/jn.00899.2002

35. Majewska MD. Neuroactive steroids, endogenous bimodal modulators of the GABA-A receptor: mechanism of action and physiological significance. Prog Neurobiol (1992) 38:379-95. doi:10.1016/0301-0082(92)90025-A
36. Calogero AE, Palumbo MA, Bosboom AMJ, Burrello N, Ferrara E, Palumbo G, et al. The neuroactive steroid allopregnanolone suppresses hypothalamic gonadotropin-releasing hormone release through a mechanism mediated by the gamma-aminobutyric acid A receptor. J Endocrinol (1998) 15:121-5. doi:10.1677/joe.0.1580121

37. Wohlfarth KM, Bianchi MT, Macdonald RL. Enhanced neurosteroid potentiation of ternary GABA-A receptors containing the $\delta$ subunit. J Neurosci (2002) 22:1541-9.

38. Abramian AM, Comenencia-Ortiz E, Modgil A, Vien TN, Nakamura Y, Moore Y, et al. Neurosteroids promote phosphorylation and membrane insertion of extrasynaptic GABA-A receptors. Proc Natl Acad Sci (2014) 111:7133. doi:10.1073/pnas.1403285111

39. Abramian AM,Comenencia-OrtizE, VithlaniM,Eva VT, SieghartW,DaviesPA, et al. Protein kinase $\mathrm{C}$ phosphorylation regulates membrane insertion of GABA-A receptor subtypes that mediate tonic inhibition. J Biol Chem (2010) 285:41795-805. doi:10.1074/jbc.M110.149229

40. Hsu FC, Waldeck R, Faber DS, Smith SS. Neurosteroid effects on GABAergic synaptic plasticity in hippocampus. J Neurophysiol (2003) 89:1929-40. doi:10.1152/jn.00780.2002

41. Maguire J, Mody I. Neurosteroid synthesis-mediated regulation of GABA-A receptors: relevance to the ovarian cycle and stress. J Neurosci (2007) 27:2155-62. doi:10.1523/JNEUROSCI.4945-06.2007

42. Reddy DS, Rogawski MA. Stress-induced deoxycorticosterone-derived neurosteroids modulate GABA-A receptor function and seizure susceptibility. J Neurosci (2002) 22:3795-805.

43. Lambert JJ, Peters JA, Struggens NC, Hales TG. Steroid modulation of the GABAA receptor complex: electrophysiological studies. Steroids and Neuronal Activity, Ciba Foundation Symposium. (Vol. 153). Chichester: John Wiley \& Sons (1990). p. 56-70.

44. Shu HJ, Eisenman LN, Jinadasa D, Covey DF, Zorumski CF, Mennerick S. Slow actions of neuroactive steroids at GABA-A receptors. J Neurosci (2004) 24:6667-75. doi:10.1523/JNEUROSCI.1399-04.2004

45. Sun C, Mtchedlishvili Z, Erisir A, Kapur J. Diminished neurosteroid sensitivity of synaptic inhibition and altered location of the $\alpha 4$ subunit of GABA-A receptors in an animal model of epilepsy. J Neurosci (2007) 27:12641-50. doi:10.1523/JNEUROSCI.4141-07.2007

46. Redd DS, Kim HY, Rogawski MA. Neurosteroid withdrawal model of perimenstrual catamenial epilepsy. Epilepsia (2001) 42:328-36. doi:10.1046/j.1528-1157.2001.10100.x

47. Chang JL, Peng HY, Wu HC, Lu HT, Pan SF, Chen MJ, et al. Acute neurosteroids inhibit the spinal reflex potentiation via GABAergic neurotransmission. Am J Physiol (2010) 299:F43-8. doi:10.1152/ajprenal. 00632.2009

48. Waters SL, Miller GW, Aleo MD, Schnellmann RG. Neurosteroid inhibition of cell death. Am Physiol Soc (1997) 273(6 Pt 2):F869-76.

49. Sousa A, Ticku MK. Interactions of the neurosteroid dehydroepiandrosterone sulfate with the GABAAReceptor complex reveals that it may act via the picrotoxin site. J Pharmacol Exp Ther (1997) 282:827-33.

50. Gartside S, Griffith N, Kaura V, Ingram C. The neurosteroid dehydroepiandrosterone (DHEA) and its metabolites alter 5-HT neuronal activity via modulation of GABA-A receptors. J Psychopharmacol (2010) 24:1717-24. doi:10.1177/0269881109105836

51. Mennerick S, Zeng CN, Benz A, Shen W, Izumi Y, Evers AS, et al. Effects on gamma-aminobutyric acid (GABA)A receptors of a neuroactive steroid that negatively modulates glutamate neurotransmission and augments GABA neurotransmission. Mol Pharmacol (2001) 60:732-41.

52. Laiprasert JD, Rogers RC, Heesch CM. Neurosteroid modulation of arterial baroreflex-sensitive neurons in rat rostral ventrolateral medulla. Am Physiol Soc (1998) 274(4 Pt 2):R903-11.

53. Li W, Jin X, Covey DF, Steinbach JH. Neuroactive steroids and human recombinant $\rho 1$ GABA-C receptors. J Pharmacol Exp Ther (2007) 323:236-47. doi:10.1124/jpet.107.127365

54. Morris KDW, Moorefield CN, Amin J. Differential modulation of the gamma-aminobutyric acid type C receptor by neuroactive steroids. Mol Pharmacol (1999) $56: 752-9$.

55. Sliwinski A, Monne TF, Schumacher M, Morin-Surun M. Pregnenolone sulfate enhances long-term potentiation in CA1 in rat hippocampus slices through the modulation of $N$-methyl-D-aspartate receptors. J Neurosci Res (2004) 78:691-701. doi:10.1002/jnr.20332 
56. Gibbs TT, Yaghoubi N, Weaver CE Jr, Park-Chung M, Russek SJ, Farb DH. ModulationofIonotropic GlutamateReceptorsbyNeuroactiveSteroids. Totowa,NJ: Humana (1999). p. 167-90.

57. Mameli M, Carta M, Partridge LD, Valenzuela CF. Neurosteroid-induced plasticity of immature synapses via retrograde modulation of presynaptic NMDA receptors.J Neurosci (2005)25:2285-94.doi:10.1523/JNEUROSCI.3877-04.2005

58. Costa ET, Olivera DS, Meyer DA, Ferreira VMM, Soto EE, Frausto S, et al. Fetal alcohol exposure alters neurosteroid modulation of hippocampal $\mathrm{N}$-methylD-aspartate receptors. J Biol Chem (2000) 275:38268-74. doi:10.1074/jbc. M004136200

59. Kostakis E, Smith C, Jang MK, Martin SC, Richards KG, Russek SJ, et al. The neuroactive steroid pregnenolone sulfate stimulates trafficking of functional $\mathrm{N}$-methyl D-aspartate receptors to the cell surface via a noncanonical, G protein, and Ca2+-dependent mechanism. Mol Pharmacol (2013) 84:261-74. doi:10.1124/mol.113.085696

60. Lau CG, Zukin RS. NMDA receptor trafficking in synaptic plasticity and neuropsychiatric disorders. Natl Rev Neurosci (2007) 8:413-26. doi:10.1038/ nrn2153

61. Uzunova V, Sheline Y, Davis JM, Rasmusson A, Uzunov DP, Costa E, et al. Increase in the cerebrospinal fluid content of neurosteroids in patients with unipolar major depression who are receiving fluoxetine or fluvoxamine. Proc Natl Acad Sci Am (1998) 95:3239-44. doi:10.1073/pnas.95.6.3239

62. Gago N, El-Etr M, Sananes N, Cadepond F, Samuel D, Avellana-Adalid V, et al. 3alpha,5alpha-Tetrahydroprogesterone (allopregnanolone) and gamma-aminobutyric acid: autocrine/paracrine interactions in the control of neonatal PSA-NCAM+ progenitor proliferation. J Neurosci Res (2004) 78:770-83. doi:10.1002/jnr.20348

63. Wang JM, Johnston PB, Ball BG, Brinton RD. The neurosteroid allopregnanolone promotes proliferation of rodent and human neural progenitor cells and regulates cell-cycle gene and protein expression. J Neurosci (2005) 25:4706-18. doi:10.1523/JNEUROSCI.4520-04.2005

64. Perrot-Sinal TS, Auger AP, McCarthy MM. Excitatory actions of GABA in developing brain are mediated by l-type $\mathrm{Ca}+2$ channels and dependent on age, sex, and brain region. Neuroscience (2003) 116:995-1003. doi:10.1016/ S0306-4522(02)00794-7

65. Ashworth R, Bolsover SR. Spontaneous activity-independent intracellular calcium signals in the developing spinal cord of the zebrafish embryo. Dev Brain Res (2002) 139:131-7. doi:10.1016/S0165-3806(02)00538-2

66. Wang M, He Y, Eisenman LN, Fields C, Zeng CM, Mathews J, et al. 3-beta-hydroxypregnane steroids are pregnenolone sulfate-like GABA(A) receptor antagonists. J Neurosci (2002) 22:3366-75.

67. Todorovic SM, Pathirathna S, Brimelow BC, Jagodic MM, Ko SH, Jiang X, et al. $5 \beta$-reduced neuroactive steroids are novel voltage dependent blockers of T-type $\mathrm{Ca}+2$ channels in rat sensory neurons in vitro and potent peripheral analgesics in vivo. Mol Pharmacol (2004) 66:1223-35. doi:10.1124/mol.104.002402

68. Robichaud M, Debonnel G. Modulation of the firing activity of female dorsal raphe nucleus serotonergic neurons by neuroactive steroids. J Endocrinol (2004) 182:11-21. doi:10.1677/joe.0.1820011

69. Karishma KK, Herbert J. Dehydroepiandrosterone (DHEA) stimulates neurogenesis in the hippocampus of the rat, promotes survival of newly formed neurons and prevents corticosterone-induced suppression. Eur J Neurosci (2002) 16(3):445-53. doi:10.1046/j.1460-9568.2002.02099.x

70. Dong LY, Zhu Y, Dong Y, Yang JH, Zhao YY, Qi YJ, et al. Neuroactive steroid dehydroepiandrosterone sulfate inhibits 5-hydroxytryptamine (5-HT)-evoked glutamate release via activation of $\sigma-1$ receptors and then inhibition of 5-HT3 receptors in rat prelimbic cortex. J Pharmacol Exp Ther (2009) 330:494-501. doi:10.1124/jpet.109.154294

71. Rasgon N, Serra M, Biggio G, Maria GP, Fairbanks L, Tanavoli S, et al. Neuroactive steroid-serotonergic interaction: responses to an intravenous L-tryptophan challenge in women with premenstrual syndrome. Eur J Endocrinol (2001) 145:25-33. doi:10.1530/eje.0.1450025

72. Ze-Min W, Ying-Jie Q, Pei-Ying W, Yan Z, Yan-Lian D, Zheng-Xiang C, et al. Neuroactive steroid pregnenolone sulphate inhibits long-term potentiation via activation of $\alpha_{2}$-adrenoreceptors at excitatory synapses in rat medial prefrontal cortex. Int J Neuropsychopharmacol (2008) 11:611-24. doi:10.1017/ S1461145707008334

73. Harteneck C. Function and pharmacology of TRPM cation channels. Naunyn Schmiedebergs Arch Pharmacol (2005) 371:307-14. doi:10.1007/ s00210-005-1034-x
74. Majeed Y, Agarwal AK, Naylor J, Seymour VA, Jiang S, Muraki K, et al. Cis-isomerism and other chemical requirements of steroidal agonists and partial agonists acting at TRPM3 channels. Br J Pharmacol (2010) 161:430-41. doi:10.1111/j.1476-5381.2010.00892.x

75. Wagner TF, Loch S, Lambert S, Straub I, Mannebach S, Mathar I, et al. Transient receptor potential M3 channels are ionotropic steroid receptors in pancreatic beta cells. Nat Cell Biol (2008) 10:1421-30. doi:10.1038/ ncb1801

76. Vriens J, Owsianik G, Hofmann T, Philipp SE, Stab J, Chen X, et al. TRPM3 is a nociceptor channel involved in the detection of noxious heat. Neuron (2011) 70:482-94. doi:10.1016/j.neuron.2011.02.051

77. Alonso G, Phan VL, Guillemain I, Saunier M, Legrand A, Anoal M, et al. Immunocytochemical localization of the $\sigma 1$ receptor in the adult rat central nervous system. Neuroscience (2000) 97:155-70. doi:10.1016/ S0306-4522(00)00014-2

78. Hayashi T, Maurice T, Su TP. Ca2+ signaling via sigma1-receptors: novel regulatory mechanism affecting intracellular $\mathrm{Ca} 2+$ concentration. J Pharmacol Exp Ther (2000) 293:788-98.

79. Romieu P, Martin-Fardon R, Bowen WD, Maurice T. $\sigma 1$ receptor-related neuroactive steroids modulate cocaine-induced reward. J Neurosci (2003) 23:3572-6.

80. Li AC, Glass CK. PPAR- and LXR-dependent pathways controlling lipid metabolism and the development of atherosclerosis. JLipid Res (2004) 45:2161-73. doi:10.1194/jlr.R400010-JLR200

81. Beaven SW, Tontonoz P. Nuclear receptors in lipid metabolism: targeting the heart of dyslipidemia. Ann Rev Med (2006) 57:313-29. doi:10.1146/annurev. med.57.121304.131428

82. Cermenati G, Giatti S, Cavaletti G, Bianchi R, Maschi O, Pesaresi M, et al. Activation of the liver $\mathrm{X}$ receptor increases neuroactive steroid levels and protects from diabetes-induced peripheral neuropathy. J Neurosci (2010) 30:11896-901. doi:10.1523/JNEUROSCI.1898-10.2010

83. Darbandi-Tonkabon R, Manion BD, Hastings WR, Craigen WJ, Akk G, Bracamontes JR, et al. Neuroactive steroid interactions with voltage-dependent anion channels: lack of relationship to GABAA receptor modulation and anesthesia. JPharmacol Exp Ther (2004) 308:502-11. doi:10.1124/ jpet.103.058123

84. Fontaine-Lenoir V, Chambraud B, Fellous A, David S, Duchossoy Y, Baulieu EE, et al. Microtubule-associated protein 2 (MAP2) is a neurosteroid receptor. Proc Natl Acad Sci U S A (2006) 103:4711-6. doi:10.1073/pnas. 0600113103

85. Lazaridis I, Charalampopoulos I, Alexaki VI, Avlonitis N, Pediaditakis I, Efstathopoulos P, et al. Neurosteroid dehydroepiandrosterone interacts with nerve growth factor (NGF) receptors, preventing neuronal apoptosis. PLoS Biolog (2011) 9:e1001051. doi:10.1371/journal.pbio.1001051

86. Gangisetty O, Reddy DS. Neurosteroid withdrawal regulates GABA-A receptor $\alpha 4$ subunit expression and seizure susceptibility by activation of PR-independent Egr3 pathway. Neuroscience (2010) 170:865-80. doi:10.1016/j. neuroscience.2010.07.037

87. Rogawski MA, Loya CM, Reddy K, Zolkowska D, Lossin C. Neuroactive steroids for the treatment of status epilepticus. Epilepsia (2013) 54:93-8. doi:10.1111/epi.12289

88. Brinton RD. The neurosteroid 3-hydroxy-5-pregnan-20-one induces cytoarchitectural regression in cultured fetal hippocampal neurons. J Neurosci (1994) 14:2763-74.

89. Monaghan EP, Navalta LA, Shum L, Ashbrook DW, Lee DA. Initial human experience with ganaxolone, a neuroactive steroid with antiepileptic activity. Epilepsia (1997) 38:1026-31. doi:10.1111/j.1528-1157.1997. tb01486.x

90. Kerrigan JF, Shields WD, Nelson TY, Bluestone DL, Dodson WE, Bourgeois BF, et al. Ganaxolone for treating intractable infantile spasms: a multicenter, open-label, add-on trial. Epilepsy Res (2000) 42:133-9. doi:10.1016/ S0920-1211(00)00170-4

91. Shulman Y, Tibbo PG. Neuroactive steroids in schizophrenia. Can J Psychiatry (2005) 50:695-702. doi:10.1177/070674370505001109

92. Van Broekhoven F, Verkes RJ. Neurosteroids in depression: a review. Psychopharmacology (2003) 165:97-110. doi:10.1007/s00213-0021257-1

93. Cohen H, Maayan R, Touati-Werner D, Kaplan Z, Matar AM, Loewentha MU, et al. Decreased circulatory levels of neuroactive steroids in behaviourally 
more extremely affected rats subsequent to exposure to a potentially traumatic experience. Int J Neuropsychopharmacol (2007) 10:203-9. doi:10.1017/ S146114570600664X

94. Strous RD, Spivak B, Yoran-Hegesh R, Maayan R, Averbuch E, Kotler M, et al. Analysis of neurosteroid levels in attention deficit hyperactivity disorder. Int JNeuropsychopharmacol (2001) 4:259-64. doi:10.1017/ S1461145701002462

95. Luchetti S, Bossers K, Van de Bilt S, Agrapart V, Morales RR, Frajese GV, et al. Neurosteroid biosynthetic pathways changes in prefrontal cortex in Alzheimer's disease. Neurobiol Aging (2011) 32:1964-76. doi:10.1016/j. neurobiolaging.2009.12.014

96. Noorbakhsh F, Ellestad KK, Maingat F, Warren KG, Han MH, Steinman L, et al. Impaired neurosteroid synthesis in multiple sclerosis. Brain (2011) 134:2703-21. doi:10.1093/brain/awr200
97. Luchetti S, Huitinga I, Swaaba DF. Neurosteroid and GABA-A receptor alterations in Alzheimer's disease, Parkinson's disease and multiple sclerosis. Neuroscience (2011) 191:6-21. doi:10.1016/j.neuroscience.2011.04.010

Conflict of Interest Statement: The authors declare that the research was conducted in the absence of any commercial or financial relationships that could be construed as a potential conflict of interest.

Copyright $(5) 2017$ Tuem and Atey. This is an open-access article distributed under the terms of the Creative Commons Attribution License (CC BY). The use, distribution or reproduction in other forums is permitted, provided the original author(s) or licensor are credited and that the original publication in this journal is cited, in accordance with accepted academic practice. No use, distribution or reproduction is permitted which does not comply with these terms. 